CNS Spectrums (2015), 20, 112-121. C Cambridge University Press 2014. The online version of this article is published within an Open Access environment subject to the conditions of the Creative Commons Attribution-NonCommercial-ShareAlike licence <http://creativecommons.org/licenses/by-nc-sa/3.0/ > . The written permission of Cambridge University Press must be obtained for commercial re-use. doi: $10.1017 /$ S1092852914000078

\title{
Daily life impairments associated with childhood/adolescent attention-deficit/hyperactivity disorder as recalled by adults: results from the European Lifetime Impairment Survey
}

\author{
Herve Caci, ${ }^{1 *}$ Philip Asherson, ${ }^{2}$ Renato Donfrancesco, ${ }^{3}$ Stephen V. Faraone, ${ }^{4}$ \\ Amaia Hervas, ${ }^{5}$ Michael Fitzgerald, ${ }^{6}$ and Manfred Döpfner ${ }^{7}$
}

\footnotetext{
${ }^{1}$ Pediatric Department, Hôpitaux Pédiatriques de Nice CHU Lenval, Nice, France

${ }^{2}$ Department of Social Genetic and Developmental Psychiatry, Institute of Psychiatry, King's College London, UK

${ }^{3}$ Child Neuropsychiatry Department, Sandro Pertini Hospital, Rome, Italy

${ }^{4}$ Department of Psychiatry and Department of Neuroscience and Physiology, SUNY Upstate Medical University, Syracuse, New York, USA

${ }^{5}$ Child and Adolescent Mental Health Unit, Hospital Universitario Mútua de Terrassa, Barcelona, Spain

${ }^{6}$ Department of Psychiatry, Trinity College, Dublin, Ireland

${ }^{7}$ Department of Child and Adolescent Psychiatry, University of Cologne, Cologne, Germany
}

Introduction. The Lifetime Impairment Survey, conducted in Europe, assessed impairment and symptoms of attentiondeficit/hyperactivity disorder (ADHD) in childhood, and experiences of ADHD diagnosis and treatment, as recalled by adults.

Methods. Adults with ADHD and without ADHD (control group) were invited to participate in an internet-based survey and report on their childhood experiences. History of ADHD diagnosis was self-reported. Groups were compared using impairment and symptom scales.

Results. Overall, 588 adults with $\mathrm{ADHD}$ and 736 without ADHD participated. Mean (standard deviation [SD]) age at diagnosis of $\mathrm{ADHD}$ was 20.0 (12.6) years (median 18.0) following consultation with 3.8 (5.1) doctors (median 2) over 44.6 (69.3) months (median 17.0). A total of 64.1\% (377/588) of adults with ADHD reported frustration or difficulties during the diagnostic process. The ADHD group had a higher mean (SD) score versus control for general (3.3 [1.2] vs 2.1 [1.2]; $p<0.001)$ and school impairment (2.8 [0.7] vs 2.3 [0.6]; $p<0.001)$ but not home impairment (2.1 [0.5] for both groups).

Discussion. The survey demonstrated that ADHD had a negative impact on all aspects of childhood investigated, as recalled by adults.

Conclusions. These data provide insights into childhood impairments and identify areas for improvement in the management and treatment of ADHD.

Received 3 December 2013; Accepted 6 January 2014; First published online 26 February 2014

Key words: ADHD, diagnosis, functional impairment, Lifetime Impairment Survey, treatment.

*Address for correspondence: H. Caci, Pediatric Department, Hôpitaux Pédiatriques de Nice CHU-Lenval, 57, Avenue de la Californie, 06200 Nice, France.

(Email: caci.h@pediatrie-chulenval-nice.fr)

Authors Herve Caci and Manfred Döpfner contributed equally to this work.

The Lifetime Impairment Survey (LIS) was funded by the sponsor, Shire Development, LLC. The steering committee included the authors of this paper and Professor L Vlasfeld (Delft, the Netherlands), who the authors thank for assistance with the study design. The authors also thank Deanne Weber, PhD (Porter Novelli Public Services, Washington, USA) for study analyses and Tamzin Redston, $\mathrm{PhD}$ (Fishawack Communications Ltd, Abingdon, UK) for preparation of the study report and assistance with previous presentations of the LIS data (all funded by Shire AG, Switzerland). Under the direction of the authors, Alyson Bexfield, PhD, and Debby Moss, PhD, employees of Caudex Medical, Oxford, UK, provided writing assistance for this publication. Editorial assistance in formatting, proofreading, copyediting, and fact checking was also provided by Caudex Medical. Shire AG, Switzerland provided funding to Caudex Medical, Oxford, UK, for support in writing and editing this manuscript. Although the sponsor was involved in the topic concept and fact checking of information, the content of this manuscript, the ultimate interpretation, and the decision to submit it for publication in CNS Spectrums was made by the authors independently. 


\section{Introduction}

Attention-deficit/hyperactivity disorder (ADHD), the most common neurobehavioral disorder in childhood, has an estimated worldwide-pooled prevalence of $5 \%$ in children and adolescents (aged $\leq 18$ years). ${ }^{1,2}$ While geographic variation in $\mathrm{ADHD}$ prevalence rates has been demonstrated, this has been attributed to methodological variation in the application of diagnostic criteria, particularly relating to the evaluation of impairment. $^{1,3,4}$ Both the prevalence and heritability of ADHD is similar across Europe, Scandinavia, North America, and Australia. ${ }^{5}$

Symptoms associated with $\mathrm{ADHD}$, which is largely considered a childhood disorder, often persist into adulthood; approximately $65 \%$ of children diagnosed with $\mathrm{ADHD}$ exhibit symptoms as adults. ${ }^{6}$ However, the majority of adults who seek assistance for $\mathrm{ADHD}$ (approximately $75 \%$ ) have not previously received a diagnosis with the disorder, and many are self-referred. ${ }^{7}$ As ADHD is a developmental disorder, diagnosis is often based on recall of childhood symptoms. Retrospective diagnoses of childhood ADHD can be problematic, as adults with ADHD may have limited recall of their childhood symptoms and, depending on their current level of symptoms, tend to underestimate the severity of the childhood stage of the disorder compared with parent ratings of $\mathrm{ADHD}$ symptoms collected in childhood. , $^{8}$

$\mathrm{ADHD}$ is associated with impairments in social, family, emotional, academic, cognitive, and behavioral functioning. ${ }^{10-12}$ Previous pan-European studies of impairments associated with ADHD in everyday life demonstrated that $\mathrm{ADHD}$ had a negative impact on familial and social relationships and on various everyday activities; however, impairments were parent-reported rather than retrospectively recalled by adults. ${ }^{13,14}$ Results from a U.S. survey investigating functional impairments recalled by adults with self-reported ADHD revealed that they were significantly more likely to have negative feelings about their childhood and adolescent years than adults without ADHD. ${ }^{15}$

The Lifetime Impairment Survey (LIS), which was conducted in 6 European countries, was designed to assess the degree to which $\mathrm{ADHD}$ impairs patients' everyday lives and to identify the areas of life most affected by the condition. ${ }^{12,16}$ The LIS, based on the previously mentioned U.S. survey, ${ }^{15}$ collected data from adults with $\mathrm{ADHD}$ and parents/caregivers of children with ADHD, for comparison with corresponding control groups. Experiences concerning ADHD care, as well as the duration and efficacy of treatment, were also assessed. Outcomes of the study related to experiences during childhood and adolescence, as recalled by adults, are reported here. We hypothesized that adults with $\mathrm{ADHD}$ would recall greater functional impairment during their childhood and adolescence relative to adults without $\mathrm{ADHD}$.

\section{Methods}

\section{Population and subject recruitment}

Participants for the survey were recruited by e-mail invitation from the GfK Global Online Panel (GfK Healthcare, London), which had a database of 487,533 members. A range of techniques are used to continuously recruit new panel members, who are informed upon enrolment about their rights and responsibilities relating to participation in survey research and then complete a demographic profiling survey. Consent is not obtained separately for each survey that panel members participate in; however, survey participation is voluntary, and panelists may leave a survey at any time. No individual identifiers are held in the database to maintain confidentiality. In exchange for participation in the LIS, responders were invited to nominate a charity to which a donation would be made and had the opportunity to enter into a prize draw.

Adults with ADHD (ADHD group) and without $\mathrm{ADHD}$ (control group) were identified using information collected during initial demographic profiling regarding whether they had ever been diagnosed with ADHD by a doctor or other healthcare professional (HCP), together with additional questions asking about ADHD in the family. Final allocation to the ADHD group was based on a response in the LIS to a question on whether a doctor or other HCP had ever diagnosed the participant with $\mathrm{ADHD}$, attention deficit disorder, or hyperkinetic disorder.

\section{Survey design}

The LIS was a pan-European survey to assess the degree to which ADHD impairs patients' everyday lives and to identify the areas of life most affected by the condition. The survey, developed in English and translated into local languages, was circulated and completed in France, Germany, Italy, Spain, the Netherlands, and the UK from May 2010 to June 2010. The study was designed and implemented by GfK Healthcare (London, $\mathrm{UK}$ ), an independent market research organization, under the direction of a steering committee of psychiatrists and psychologists who treat and research ADHD. The steering committee included the authors, representatives from each country surveyed, and the study sponsor (Shire Development, LLC). The survey was conducted in accordance with industry guidelines from the British Healthcare Business Intelligence Association, ${ }^{17}$ European Pharmaceutical Market Research Association, ${ }^{18}$ Market Research Society, ${ }^{19}$ and World Association of Research Professionals. ${ }^{20}$ As the survey 
TABLE 1. ADHD impairment and symptom scale scores

\begin{tabular}{|c|c|c|c|c|}
\hline \multirow{2}{*}{ Scale } & \multirow{2}{*}{ Number of items per scale } & \multirow{2}{*}{ Cronbach's alpha $^{a}$} & \multicolumn{2}{|c|}{ Mean (SD) score } \\
\hline & & & ADHD group $(N=499)$ & Control group $(N=640)$ \\
\hline General impairment ${ }^{*}$ & 4 & 0.92 & $3.3(1.2)$ & $2.1(1.2)$ \\
\hline ADHD symptom ${ }^{*}$ & 8 & 0.84 & $3.5(0.7)$ & $2.6(0.8)$ \\
\hline Comorbid symptom $^{*}$ & 8 & 0.82 & $3.4(0.7)$ & $2.6(0.8)$ \\
\hline School failure $^{*}$ & 2 & 0.43 & $1.4(1.2)$ & $0.7(0.9)$ \\
\hline School impairment ${ }^{*}$ & 9 & 0.80 & $2.8(0.7)$ & $2.3(0.6)$ \\
\hline Relationship impairment ${ }^{*}$ & 7 & 0.87 & $2.7(1.0)$ & $2.3(0.8)$ \\
\hline Home impairment & 7 & 0.78 & $2.1(0.5)$ & $2.1(0.5)$ \\
\hline
\end{tabular}

${ }^{a}$ Measure of internal consistency; ${ }^{*} p<0.001$ between groups; Student's $t$-test.

ADHD, attention-deficit/hyperactivity disorder; SD, standard deviation.

was conducted as market research, ethics committee approval was not obtained.

The survey comprised 55 questions divided into 4 sections: screening and classification (eg, sex, age, educational attainment, relationship status, employment status, income); impairment in childhood/adolescence (eg, impact of ADHD at school and on peer and family relationships) and general well-being (presence of conduct problems and comorbidities); impairment in adulthood (eg, impact on work, social life, relationships, and personal finances); and $\mathrm{ADHD}$ diagnosis and treatment (including satisfaction with current prescribed medicine). Adults were asked to recall their own experiences in childhood/adolescence. Data were collected from survey respondents using computer-assisted Web interviewing.

\section{Development of adult recall impairment and symptom scales}

Seven impairment and symptom scales were constructed from items pre-selected by the LIS steering committee to compare reported impairments between the ADHD and control groups (Table 1; Supplementary material can be found at: http://dx.doi.org/10.1017/S1092852914000078). The majority of the individual items for the impairment and symptom scales were adapted from Biederman et al. ${ }^{15}$ Items were grouped into scales by the steering committee based on expert consensus and face validity. Item selection for each scale was confirmed using principal components analysis and evaluated using Cronbach's alpha. Internal consistencies were good to excellent, except for the home impairment scale $(\alpha=0.78)$ and school failure scale $(\alpha=0.43$; Table 1$)$. Scales were reversed as necessary so that higher scores indicated greater impairment $(\mathrm{eg}$, the school impairment scale).

\section{Statistical analyses}

Results were analyzed for all respondents answering each item under each question unless stated otherwise.
Respondents were not required to answer all questions, and no data imputation was applied. The ADHD and control groups were compared using $t$-tests for continuous data and chi-square tests for categorical data. For graphing purposes, top-2 box comparisons (eg, combining responses "strongly agree" and "somewhat agree") were used to show differences between groups for some individual items within the scales. Analysis of covariance (ANCOVA) and StudentNewman-Keuls post hoc tests were used to investigate the effect of study group, country, and sex on age, and logistic regression was used to examine the effect of age and study group on employment. The effect of country on experiences of ADHD management was investigated using one-way analysis of variance (ANOVA). Mean impairment and symptom scale scores were calculated for all respondents who answered at least half of the questions in a particular scale; only respondents with scores on all applicable scales were included in scalerelated analyses. The effect of study group, country, age, and sex on the impairment and symptom scales and scores was analyzed using ANCOVA. Effect sizes are indicated using Cohen's $d$ and partial eta-squared. No formal sample-size calculation was performed; however, a quota of 100 respondents per study group per participating country was applied. Statistical analyses were conducted using IBM SPSS version 16.0 (Armonk, New York, USA).

\section{Findings}

\section{Participants}

Overall, 1365 adults responded to the survey. However, 41 respondents who provided impossible answers (eg, length of time until diagnosis greater than respondent's age) were removed from the database, which left a total of 1324 participants (588 in the ADHD group; 736 in the control group). Overall survey response rates are 
TABLE 2. Demographic characteristics of respondents with ADHD and without ADHD (control group)

\begin{tabular}{|c|c|c|}
\hline Characteristic & ADHD group $(N=588)$ & Control group $(N=736)$ \\
\hline Mean (SD) age, years ${ }^{\star *},+$ & $35.5(15.2)$ & $46.0(15.1)$ \\
\hline \multicolumn{3}{|l|}{ Sex, n (\%) } \\
\hline Male & $272(46.3)$ & $365(49.6)$ \\
\hline \multicolumn{3}{|l|}{ Current relationship status, $n(\%)^{* *, \pm}[578 / 722]$} \\
\hline Single, without steady partner & $208(36.0)$ & $267(37.0)$ \\
\hline Married & $159(27.5)$ & $268(37.1)$ \\
\hline Living with steady partner, but not married & $137(23.7)$ & $117(16.2)$ \\
\hline Have a steady partner but not living with him/her & $74(12.8)$ & $70(9.7)$ \\
\hline \multicolumn{3}{|l|}{ Education level, n (\%) [583/735] } \\
\hline Low & $18(3.1)$ & $15(2.0)$ \\
\hline Medium & $281(48.2)$ & 391 (53.2) \\
\hline High & $284(48.7)$ & $329(44.8)$ \\
\hline \multicolumn{3}{|l|}{ Employment status, $n(\%)^{* *, \&}[588 / 736]$} \\
\hline Employed full-time & $291(49.5)$ & $275(37.4)$ \\
\hline Employed part-time & $98(16.7)$ & $103(14.0)$ \\
\hline Student & $50(8.5)$ & $38(5.2)$ \\
\hline Retired & $16(2.7)$ & $144(19.6)$ \\
\hline Unemployed & $82(13.9)$ & 106 (14.4) \\
\hline Homemaker & $27(4.6)$ & $35(4.8)$ \\
\hline Other & $24(4.1)$ & $35(4.8)$ \\
\hline \multicolumn{3}{|l|}{ Community type, $n(\%)^{*}[563 / 716]$} \\
\hline Urban (within a city) & $304(54.0)$ & $334(46.6)$ \\
\hline Suburban (in the suburbs of a city or in a town) & $163(29.0)$ & $204(28.5)$ \\
\hline Rural (in the country) & $96(17.1)$ & $178(24.9)$ \\
\hline \multicolumn{3}{|l|}{ Personal income, 1000 Euros $^{a}$} \\
\hline Total, mean (SD) [414/474] & $22.1(23.1)$ & $20.5(19.4)$ \\
\hline Employed only, mean (SD) [294/250] & $26.4(24.1)$ & $24.5(20.8)$ \\
\hline \multicolumn{3}{|c|}{$\begin{array}{l}\text { Numbers in square brackets represent number of respondents in the ADHD group and control group, respectively. } \\
{ }^{a} \text { Personal incomes were normalized and individuals with income }>2.5 \mathrm{SD} \text { above the mean were set to missing. } \\
\left.{ }^{\star} p<0.01 ;{ }^{* \star} p<0.001 ;{ }^{+} \text {Cohen's } d=0.693 ;{ }^{\ddagger} \text { chi-squared (df } 3, \mathrm{~N}=1300 \text { ) }=21.1 ;{ }^{\S} \text { Chi-squared (df } 6\right)=95.4 \text {. } \\
\text { ADHD, attention-deficit/hyperactivity disorder; df, degrees of freedom; SD, standard deviation. }\end{array}$} \\
\hline
\end{tabular}

not available, as the number of outgoing invitations was not tracked.

The number of respondents in the $\mathrm{ADHD}$ group per country ranged from 89 in Italy to 96 in Germany, 97 in Spain, 100 each in France and the UK, and 106 in the Netherlands. Demographic characteristics of respondents are presented in Table 2. The ADHD group was approximately 10 years younger than the control group (mean [standard deviation (SD)] age 35.5 [15.2] years vs 46.0 [15.1] years; Student's $t$-test [degrees of freedom (df) 1255$]=12.5, p<0.001$, Cohen's $d=0.693$ ); however, all significant scale results remained significant when adjusted for group differences using adult age as a covariate, and when younger $(<45$ years $)$ and older ( $\geq 45$ years) adults were examined separately. Further investigation into respondent age using ANCOVA demonstrated a significant difference in age between countries $(F$ test $[\mathrm{df} 5,1131]=4.4 ; p=0.001$, partial eta-squared 0.019) and between study groups ( $F$ test [df 1,1131$]=153.0 ; p<0.001$, partial eta-squared $0.119)$, but not between the sexes $(F$ test [df 1 , $1131]=3.5 ; p=0.063$, partial eta-squared 0.003). Student-Newman-Keuls post hoc tests indicated that the ADHD group had a significantly higher mean age in Italy (40.3 years) versus the UK, the Netherlands, and Spain (32.1, 33.8, and 34.6 years, respectively), while conversely in the control group, respondents from the Netherlands were significantly older (52.2 years) than those from Spain and Italy (41.4 and 41.6 years, respectively). Adults with $\mathrm{ADHD}$ were more likely to be currently employed, less likely to be married, and less likely to live in rural areas than adults without $\mathrm{ADHD}$ (Table 2). An analysis was performed to examine whether a significant difference in age between study groups could explain why the $\mathrm{ADHD}$ group was more likely to be in current employment than the control group. A logistic regression showed that age, study group, and the interaction between age and study group were weak predictors of employment status (Cox and Snell R square 0.065, Nagelkerke R square 0.088; Table 3).

\section{Experiences of ADHD management}

Approximately half of the adults (51.9\%; 305/588) were aged 18 years or older when a diagnosis of ADHD was received. Mean (SD) age at diagnosis of $\mathrm{ADHD}$ was 
TABLE 3. Logistic regression examining education level based on age and study group

\begin{tabular}{|c|c|c|c|c|c|c|c|}
\hline & & \multicolumn{6}{|c|}{ Variables in the equation } \\
\hline & & B & SE & Wald & df & $p$ & $\operatorname{Exp}(B)^{a}$ \\
\hline \multirow[t]{6}{*}{ Step $1^{b}$} & Age & -0.039 & 0.006 & 46.576 & 1 & 0.000 & 0.961 \\
\hline & Study group & -1.040 & 0.381 & 7.450 & 1 & 0.006 & 0.353 \\
\hline & Age by study group & 0.035 & 0.009 & 15.736 & 1 & 0.000 & 1.036 \\
\hline & Constant & 1.922 & 0.281 & 46.707 & 1 & 0.000 & 6.834 \\
\hline & & \multicolumn{6}{|c|}{ Model summary } \\
\hline & & -2 Log likelihood & Cox \& Snell R square & Nagelkerke R square & & & \\
\hline Step 1 & & $1464.113^{c}$ & 0.065 & 0.088 & & & \\
\hline
\end{tabular}

20.0 (12.6) years (median 18.0; ranging from 17.6 [11.1] years in Spain to 21.8 [12.5] years in France) following consultation of 3.8 (5.1) doctors (median 2.0; ranging from 3.1 [2.8] in Germany to 4.7 [6.6] in Italy) over a period of 44.6 (69.3) months (median 17.0; ranging from 33.6 [51.6] months in Germany to 62.9 [76.2] months in Italy). One-way ANOVA showed no significant differences between countries in age at diagnosis ( $F$ test [df 5,587$]=2.2 ; p=0.049)$, time to diagnosis $(F$ test [df 5,325$]=1.2 ; p=0.303)$, or the number of doctors seen before diagnosis $(F$ test $[\mathrm{df} 5,587]=1.1 ; p=0.358)$. The majority $(64.1 \% ; 377 / 588)$ of adults reported frustration or difficulties during the diagnostic process, particularly with the number of visits $(29.3 \% ; 172 / 588)$ or doctors consulted $(30.4 \%$; 179/588) before diagnosis, but also with receiving at least 1 misdiagnosis with a condition other than ADHD $(26.5 \% ; 156 / 588)$ or having a doctor who was skeptical about $\mathrm{ADHD}$ as a pediatric condition $(24.5 \% ; 144 / 588)$.

Approximately one-quarter of adults with ADHD were receiving prescription medication for ADHD (26.4\%; $155 / 588)$, either alone $(11.2 \% ; 66 / 588)$ or in combination with behavioral interventions $(15.1 \%, 89 / 588)$. One-third of adults were receiving behavioral interventions only $(32.1 \% ; 189 / 588)$, while $41.5 \%$ (244/588) were receiving other non-prescription alternatives or no treatment. While the majority of adults were "completely" or "somewhat" satisfied with their current prescription medication $(66.2 \% ; 133 / 201)$, most also felt that the treatment could be improved with regard to fewer side effects $(72.1 \%$; 145/201), longer duration of action $(70.8 \%$; 143/202), better efficacy $(70.0 \%$; $140 / 200)$, faster onset of action (68.3\%; 136/199), smoother delivery profile to prevent a sudden rise or fall in behavioral characteristics and reduce withdrawal symptoms $(67.2 \% ; 135 / 201)$, and lower frequency of dose $(57.3 \%$; 114/199).

The majority of adults with ADHD (86.4\%; 508/588) reported having received a diagnosis of 1 or more co-existing conditions $(25.0 \%$ [147/588] reported 1 , $12.6 \%$ [74/588] reported $2,11.7 \%$ [69/588] reported 3 , and $37.1 \%$ [218/588] reported 4 or more). Depression was the most frequently reported comorbidity $(42.2 \%$; 248/588; Figure 1).

\section{Recalled childhood ADHD impairment and symptom scale scores}

Only respondents who had scores on all applicable scales were included in the impairment and symptom scale analyses $(86.0 \%$ [1139/1324]; 499 adults with $\mathrm{ADHD}$ and 640 adults without $\mathrm{ADHD})$. The only demographic difference between excluded $(n=185)$ and included $(\mathrm{n}=1139)$ respondents was education level (chi-squared test [df 2] $=16.9 ; p<0.001$ ); a greater number of included respondents had a high level of education compared with excluded respondents (48.4\% [550/1137] vs $34.8 \%$ [63/181]).

Impairments from childhood and adolescence recalled by the ADHD group were significantly greater than those recalled by the control group in all scales except home impairment $(p<0.001$; Table 1$)$.

The effect of study group, country, sex, and age on the impairment and symptom scales examined using ANCOVA showed that the study group (ADHD or control group) had the greatest effect on impairment and symptom scale scores, with a medium-to-large effect size for all scales except home impairment; most notably the ADHD symptom scale (partial eta-squared 0.21; $p<0.001$ ), comorbid symptoms (partial eta-squared 


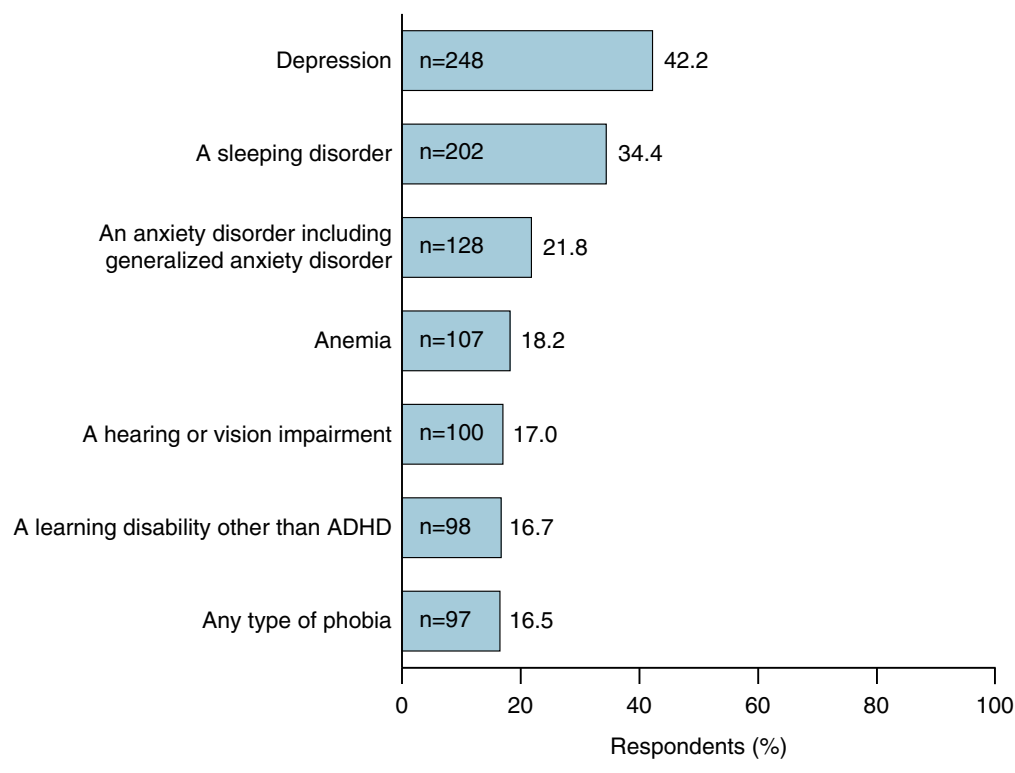

$\mathrm{ADHD}$, attention-deficit/hyperactivity disorder

FIGURE 1. Co-existing conditions in the ADHD group. Most frequent co-existing conditions diagnosed by a doctor or other healthcare professional, as reported by adults with ADHD. Respondents could select multiple conditions.

TABLE 4. Summary of ANCOVA on recalled impairment and symptom scales

\begin{tabular}{|c|c|c|c|c|}
\hline \multirow[b]{2}{*}{ Impairment and symptom scales } & \multicolumn{4}{|c|}{ Source } \\
\hline & Sample & Country & Sex & Age \\
\hline General impairment & $187.8(1), 0.14^{*}$ & $4.1(5), 0.02^{*}$ & ns & ns \\
\hline ADHD symptom & $296.2(1), 0.21^{*}$ & $5.4(5), 0.02^{*}$ & ns & 11.5 (1), $0.01^{*}$ \\
\hline Comorbid symptom & $224.0(1), 0.17^{*}$ & $6.2(5), 0.03^{*}$ & 16.0 (1), $0.01^{*}$ & 22.7 (1), $0.02^{*}$ \\
\hline School failure & $97.5(1), 0.08^{*}$ & $5.4(5), 0.02^{*}$ & $11.9(1), 0.01^{*}$ & $15.8(1), 0.01^{*}$ \\
\hline School impairment & $103.3(1), 0.08^{*}$ & $8.3(5), 0.04 *$ & ns & ns \\
\hline Relationship impairment & $51.0(1), 0.04^{*}$ & $6.1(5), 0.03^{*}$ & ns & ns \\
\hline Home impairment & ns & $11.0(5), 0.05^{*}$ & $11.8(1), 0.01^{*}$ & ns \\
\hline
\end{tabular}

${ }^{*} F$ test (degrees of freedom), partial eta-squared, reported for each significant source $(p \leq 0.001)$.

$\mathrm{ADHD}$, attention-deficit/hyperactivity disorder; ANCOVA, analysis of covariance; ns, not significant.

$0.17 ; p<0.001)$, and the general impairment scale (partial eta-squared $0.14 ; p<0.001$; Table 4 ). The effect of country was significant for all impairment and symptom scales $(p \leq 0.001)$; however, effect sizes were minor relative to the importance of study group (partial eta-squared 0.02-0.05). Small effects were also observed for the home impairment, comorbid symptom, and school failure scales for sex (partial eta-squared 0.01; $p \leq 0.001$ ); and the ADHD symptom, comorbid symptom, and school failure scales for age (partial eta-squared $0.01-0.02 ; p \leq 0.001)$.

\section{General impairment}

Significantly more adults in the ADHD group than in the control group responded that their experiences during their childhood and teenage years had a significant and negative impact on their successes in later life $(p<0.001$; Figure 2).

\section{Impairment at school}

Regarding their experiences in secondary education, significantly more adults with ADHD recalled being in the bottom of their class compared with the control group (22.7\% [125/550] vs 9.9\% [70/705]; chi-squared test [df 2] $=38.7 ; p<0.001)$, having a tutor to help with schoolwork $(25.0 \%$ [147/588] vs 9.4\% [69/736]; chi-squared test $[\mathrm{df} 1]=58.5 ; p<0.001)$, taking a special class to get extra help with schoolwork (28.9\% [170/588] vs $10.1 \%$ [74/736]; chi-squared test [df 1] $=77.3 ; p<0.001)$, and being expelled or suspended (29.6\% [174/588] vs 9.1\% [67/736]; chi-squared test $[\mathrm{df} 1]=92.2 ; p<0.001)$. 


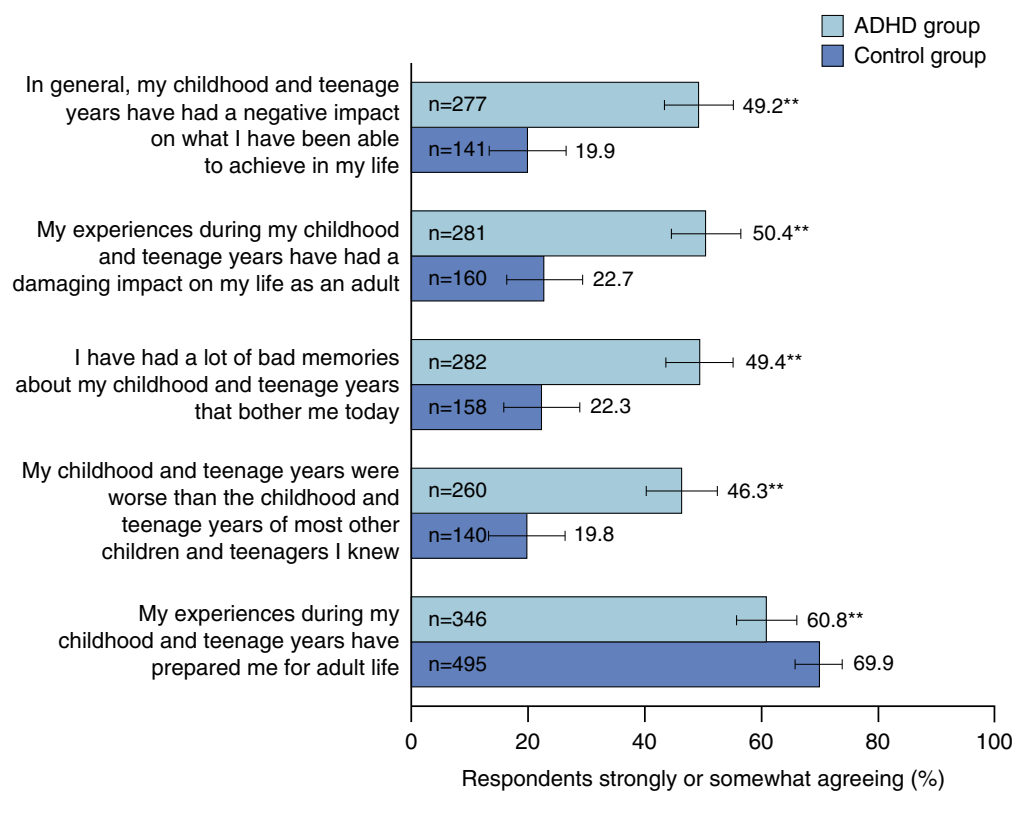

${ }^{* *} \mathrm{p}<0.001$; chi-squared test

Error bars, $95 \%$ confidence intervals

FIGURE 2. General impairment. The effect of recalled childhood and adolescent experiences on everyday life, as reported by adults with ADHD (ADHD group) and without ADHD (control group). ADHD, attention-deficit/hyperactivity disorder.

\section{Impairment at home}

Relationships with peers, siblings, and parents during childhood and adolescence were significantly impaired in the ADHD group compared with the control group (Figure 3a); however, a greater number of adults in the ADHD group than the control group recalled that they were more likely to go out on dates compared with others their age (29.3\% [161/ 549] vs $21.5 \%$ [148/687]; chi-squared [df 1] $=9.9$; $p<0.01$ ). Some areas of home life did not significantly differ between the groups, for example, time spent with friends and participation in sports, extracurricular cultural/educational activities, or school clubs (Figure 3b).

\section{Behavior and conduct problems}

The ADHD group reported significantly higher occurrence of behavioral and conduct problems during childhood and teenage years compared with the control group, including weight control (13.0\% [34/262] vs $4.5 \%$ [13/290]; chi-squared test [df 2] $=26.6 ; p<0.001$ ), smoking (14.1\% [36/255] vs 3.3\% [8/244]; chi-squared test $[\mathrm{df} 2]=22.2 ; p<0.001)$, being involved in an automobile accident while driving $(18.5 \%$ [23/124] vs $6.0 \%$ [8/133]; chi-squared test [df 2] $=12.1 ; p<0.01$ ), and receiving more than 1 speeding ticket in a 12-month period $(17.6 \%$ [18/102] vs $1.8 \%$ [1/56]; chi-squared test [df 2] $=16.7 ; p<0.001)$.

\section{Discussion}

The LIS study provides the first large community study conducted in Europe to evaluate experiences of ADHD diagnosis and management, and impairment and symptoms of ADHD in childhood, as reported retrospectively by adults with self-reported ADHD.

Results from this study should be considered in the context of the study limitations. Although the LIS was based on a previously used survey, ${ }^{15}$ it has not been formally validated and normed. The impairment and symptoms scales did, however, have good internal consistencies. Diagnosis of ADHD was self-reported and not confirmed, and those with ADHD who responded to the invitation to participate in the survey may not be representative of all adults with ADHD. Survey respondents represented a select, well-educated, information technology-literate population willing to participate in the survey. As such, awareness of symptoms and impairments associated with $\mathrm{ADHD}$, as well as motivation to seek diagnosis or treatment, may be greater in this group of respondents than in the general population. Adults in the ADHD group were significantly younger than those without ADHD (by approximately 10 years); therefore, differences between groups could reflect differences in maturity and life experiences. Respondents in the ADHD group were also more likely to be currently employed; while this is likely due to the greater proportion of retired respondents in the control group (19.6\%) compared with the ADHD 
(a)

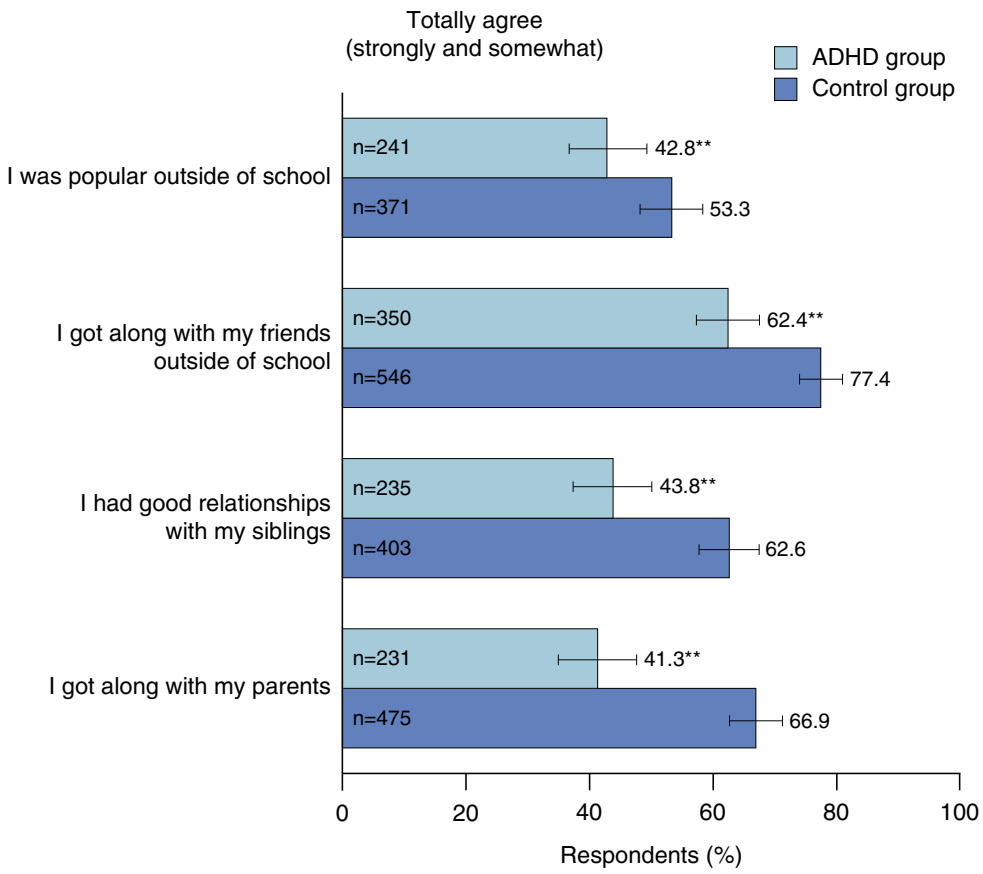

(b)

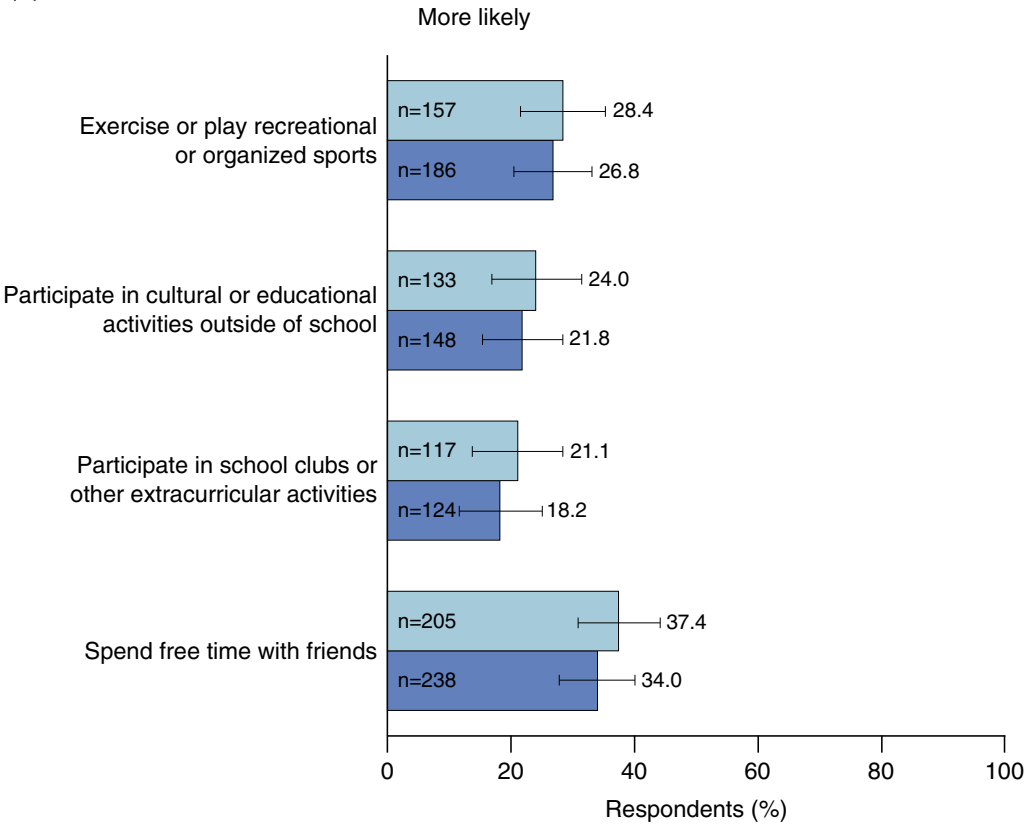

${ }^{\star *} \mathrm{p}<.001$, chi-squared test. Error bars, $95 \%$ confidence intervals.

FIGURE 3. Impairment at home. Impairment at home as recalled by adults with ADHD and without ADHD (control group). (a) Items with greatest reported differences between groups; (b) items with least reported differences between groups. ADHD, attention-deficit/hyperactivity disorder.

group $(2.7 \%)$, it could reflect bias in subject recruitment. Furthermore, Internet access and use may be more frequent in urban areas, accounting for the majority of respondents living within a city and perhaps introducing a further selection bias. Although some participants were excluded based on obvious impossible answers, no other control for other potential data entry errors could be applied, and there was no data quality assurance. Despite these limitations, the findings from this study are consistent with those reported in previous clinical and epidemiological studies of ADHD in adulthood (see Kooij et $\mathrm{al}^{21}$ for an overview).

Approximately half of the ADHD group respondents $(51.9 \%)$ were at least 18 years old when a diagnosis of 
ADHD was received, and the majority (64.1\%) reported frustration with the diagnostic process, in particular the number of visits or doctors consulted before diagnosis. Prescription medication and behavioral interventions were the most common forms of treatment; approximately one-third of adults with ADHD (32.1\%) currently received behavioral interventions only, while $15.1 \%$ were receiving both prescription medication and behavioral interventions and $41.5 \%$ were receiving nonprescription alternatives or no $\mathrm{ADHD}$ treatment. As clinical guidelines for ADHD therapy in adults advise the use of medication in the context of a comprehensive, multimodal program of treatments, the proportion of adults with $\mathrm{ADHD}$ receiving both prescription medication and behavioral interventions could be considered low. $^{21}$ The majority of patients $(66.2 \%)$ were satisfied with their prescription medication but did identify certain areas for improvement, including better control of ADHD symptoms, fewer side effects, faster onset of action, and longer duration of action to provide symptom control throughout the day into the evening. A broad range of comorbidities was associated with $\mathrm{ADHD}$, with over a third $(37.1 \%)$ of adults reporting 4 or more comorbid conditions, which may contribute to misdiagnosis of ADHD in adults. ${ }^{22}$ Consistent with previous findings, ${ }^{23-25}$ depression and anxiety disorders were among the most frequently reported coexisting psychiatric comorbidities in the ADHD group.

The survey demonstrated that ADHD had a negative impact on childhood from the retrospective perspective of the adult patients. Impairments recalled by adults with ADHD were all significantly greater than those reported by a corresponding control population, apart from those relating to home life (eg, spending time with family and friends). ANCOVA indicated that impairment rates differed among countries, but effect sizes were small (accounting for $2-5 \%$ of variance) compared with the effect of study group (ADHD vs control group: accounting for $4-21 \%$ of variance).

With regard to experiences at secondary school, consistent with previous findings on recalled educational impairment in $\mathrm{ADHD},{ }^{15}$ adults with $\mathrm{ADHD}$ were also more likely to be bottom of the class, have a tutor, or take an extra class to help with school work, and were more likely to be expelled or suspended. Relationships with family and peers were also impaired in the ADHD group compared with the control group; however, not all aspects of home life were affected, and adults with $\mathrm{ADHD}$ recalled that they were more likely to go out on dates than others their age. While this is in contrast with previous findings of the U.S.-based survey, ${ }^{15}$ it is consistent with studies showing that adults with ADHD have more partners than those without the disorder. ${ }^{26}$ Adults with ADHD also recalled more incidences of behavioral or conduct problems than adults without ADHD, which is consistent with previous findings. ${ }^{15}$

\section{Conclusions}

The LIS provides a novel insight into the childhood impairments associated with $\mathrm{ADHD}$ as recalled by adults and identifies areas for improvement in the management and treatment of the condition.

\section{Disclosure}

Herve Caci received consulting income from Shire in the past year. Philip Asherson received research or educational grants from Shire, Janssen-Cilag, Vifor, and QBTech. He has been a consultant on behalf of Kings College London for Shire, Eli Lilly, Janssen-Cilag, and Flynn Pharma and a speaker at meetings sponsored by Flynn Pharma, Eli Lilly, Shire, Janssen-Cilag, and Vifor. Renato Donfrancesco received consulting income from Shire and Novartis and received financial support from Shire and Eli-Lilly for participation in congresses. Stephen V. Faraone received consulting income, travel expenses, and/or research support from Akili Interactive Labs, Alcobra, VAYA Pharma, and SynapDx and research support from the National Institutes of Health (NIH). His institution is seeking a patent for the use of sodium-hydrogen exchange inhibitors in the treatment of ADHD. In previous years, he received consulting fees, was on advisory boards, or participated in continuing medical education programs sponsored by: Shire, Alcobra, Otsuka, McNeil, Janssen, Novartis, Pfizer, and Eli Lilly. He receives royalties from books published by Guilford Press: Straight Talk about Your Child's Mental Health and Oxford University Press: Schizophrenia: The Facts. Amaia Hervas has been on advisory boards for Janssen, Eli Lilly, and Shire. Michael Fitzgerald has been on advisory boards, and received conference attendance support, from Shire, Eli Lilly, and Janssen-Cilag. Manfred Döpfner received consulting income and research support from Eli Lilly, Medice, Shire, and Vifor, and research support from the German Research Foundation, German Ministry of Education and Research. He receives royalties from books and psychological tests published by Hogrefe, Beltz, and Huber.

\section{REFERENCES:}

1. Polanczyk G, de Lima MS, Horta BL, Biederman J, Rohde LA. The worldwide prevalence of ADHD: a systematic review and metaregression analysis. Am J Psychiatry. 2007; 164(6): 942-948.

2. Willcutt EG. The prevalence of DSM-IV attention-deficit/ hyperactivity disorder: a meta-analytic review. Neurotherapeutics. 2012; 9(3): 490-499. 
3. Buitelaar JK, Barton J, Danckaerts M, et al. A comparison of North American versus non-North American ADHD study populations. Eur Child Adolesc Psychiatry. 2006; 15(3): 177-181.

4. Dopfner M, Steinhausen HC, Coghill D, et al. Cross-cultural reliability and validity of ADHD assessed by the ADHD Rating Scale in a pan-European study. Eur Child Adolesc Psychiatry. 2006; 15(Suppl 1): I46-I55.

5. Faraone SV, Mick E. Molecular genetics of attention deficit hyperactivity disorder. Psychiatr Clin North Am. 2010; 33(1): 159-180.

6. Faraone SV, Biederman J, Mick E. The age-dependent decline of attention deficit hyperactivity disorder: a meta-analysis of follow-up studies. Psychol Med. 2006; 36(2): 159-165.

7. Faraone SV, Spencer TJ, Montano CB, Biederman J. Attentiondeficit/hyperactivity disorder in adults: a survey of current practice in psychiatry and primary care. Arch Intern Med. 2004; 164(11): 1221-1226.

8. Barkley RA, Fischer M, Smallish L, Fletcher K. The persistence of attention-deficit/hyperactivity disorder into young adulthood as a function of reporting source and definition of disorder. J Abnorm Psychol. 2002; 111(2): 279-289.

9. Miller CJ, Newcorn JH, Halperin JM. Fading memories: retrospective recall inaccuracies in ADHD. J Atten Disord. 2010; 14(1): 7-14.

10. DuPaul GJ, McGoey KE, Eckert TL, VanBrakle J. Preschool children with attention-deficit/hyperactivity disorder: impairments in behavioral, social, and school functioning. J Am Acad Child Adolesc Psychiatry. 2001; 40(5): 508-515.

11. Wilson JM, Marcotte AC. Psychosocial adjustment and educational outcome in adolescents with a childhood diagnosis of attention deficit disorder. J Am Acad Child Adolesc Psychiatry. 1996; 35(5): 579-587.

12. Caci H, Asherson P, Doepfner M, et al. Attention deficit/ hyperactivity disorder is associated with impairment in everyday life as reported by parents of affected children: results of the European Lifetime Impairment Study (Abstract P-30-04). ADHD Attention Deficit Hyperactivity Disorders. 2011; 3(2): 197.

13. Coghill D, Soutullo C, d'Aubuisson C, et al. Impact of attentiondeficit/hyperactivity disorder on the patient and family: results from a European survey. Child Adolesc Psychiatry Ment Health. 2008; 2(1): 31.

14. Riley AW, Spiel G, Coghill D, et al. Factors related to health-related quality of life (HRQoL) among children with ADHD in Europe at entry into treatment. Eur Child Adolesc Psychiatry. 2006;

15(Suppl 1): I38-I45
15. Biederman J, Faraone SV, Spencer TJ, et al. Functional impairments in adults with self-reports of diagnosed ADHD: a controlled study of 1001 adults in the community. J Clin Psychiatry. 2006; 67(4): 524-540.

16. Hervas A, Asherson P, Caci H, et al. Parental experiences of diagnosis and treatment of attention deficit/hyperactivity disorder in children: results from the European Lifetime Impairment Survey (Abstract P-31-01). ADHD Attention Deficit Hyperactivity Disorders. 2011; 3(2): 199.

17. British Healthcare Business Intelligence Association. Legal and ethical guidelines. 2012. http://www.bhbia.org.uk/guidelines/ legalandethicalguidelines/tabid/143/default.aspx. Last accessed January 20, 2012.

18. European Pharmaceutical Market Research Association. EphMRA code of conduct. 2012. http://www.ephmra.org/standardscode.aspx. Last accessed January 20, 2012.

19. Market Research Society. Code of conduct. 2012. http:// www.mrs.org.uk/standards/codeconduct.htm. Last accessed January 20, 2012.

20. World Association of Research Professionals. Codes and guidelines. 2012. http://www.esomar.org/knowledge-and-standards/codesand-guidelines.php. Last accessed January 20, 2012.

21. Kooij SJ, Bejerot S, Blackwell A, et al. European consensus statement on diagnosis and treatment of adult ADHD: The European Network Adult ADHD. BMC Psychiatry. 2010; 10: 67.

22. Montano CB, Weisler R. Distinguishing symptoms of ADHD from other psychiatric disorders in the adult primary care setting. Postgrad Med. 2011; 123(3): 88-98.

23. Hodgkins P, Montejano L, Sasane R, Huse D. Cost of illness and comorbidities in adults diagnosed with attention-deficit/ hyperactivity disorder: a retrospective analysis. Prim Care Companion CNS Disord. 2011; 13(2): PCC.10m01030.

24. Friedrichs B, Igl W, Larsson H, Larsson JO. Coexisting psychiatric problems and stressful life events in adults with symptoms of ADHD-a large Swedish population-based study of twins. J Atten Disord. 2012; 16(1): 13-22.

25. Kessler RC, Adler L, Barkley R, et al. The prevalence and correlates of adult ADHD in the United States: results from the National Comorbidity Survey Replication. Am J Psychiatry. 2006; 163(4): 716-723.

26. Barkley RA, Fischer M, Smallish L, Fletcher K. Young adult outcome of hyperactive children: adaptive functioning in major life activities. J Am Acad Child Adolesc Psychiatry. 2006; 45(2): 192-202. 